\title{
Difficult situation in cancer pain: breakthrough pain*
}

\author{
Situação difícil em dor oncológica: dor do tipo breakthrough
}

Rafael Toledo Enes Nogueira1, Érica Brandão de Moraes Vieira², Luis Henrique Albuquerque Sousa ${ }^{1}$, João Batista Santos Garcia ${ }^{3}$

${ }^{*}$ Received from Federal University of Maranhão, Pain Academic League, São Luis, MA, Brazil.

DOI 10.5935/1806-0013.20140010

\section{ABSTRACT}

BACKGROUND AND OBJECTIVES: Breakthrough pain is frequent among cancer patients and is poorly studied in Brazil. This study aimed at evaluating the characteristics of breakthrough pain and at comparing its evolution during three days. METHODS: This is a longitudinal study where a specific questionnaire developed for the study was applied and was made up of sociodemographic data (age, gender, marital status, profession, income, origin), cancer-related data (types of primary tumor, presence of metastases, therapeutic approach with chemotherapy and/or radiotherapy, surgical treatment and drugs) and parameters related to breakthrough pain (number of daily episodes, duration of crisis, intensity, pain onset velocity and types of breakthrough pain: spontaneous, incidental, drug failure at the end of the dose).

RESULTS: Most patients were females (71.7\%), aged between 30 and 50 years $(41.7 \%)$, under concomitant chemotherapy and radiotherapy $(41.7 \%)$ and had cervical cancer (54.2\%). Mean pain intensity was 7 , with standard deviation of 2.3 . With regard to breakthrough pain, there have been no statistically significant differences in the three evaluation moments. During the three evaluations, it was observed that there has been decrease in the percentage of patients with pain for more than 15 minutes in the third evaluation $(\mathrm{p}=0.004)$. There has been no difference in pharmacological profile among the three evaluations $(\mathrm{p}=0.34)$.

CONCLUSION: Breakthrough pain was frequent among the studied population. The use of opioids was effective to decrease pain duration and spontaneous pain.

Keywords: Cancer pain, Incidental pain, Irruptive pain, Opioid.

1. Federal University of Maranhão, Pain Academic League, São Luis, MA, Brazil

2. University of São Paulo, São Paulo, SP, Brazil.

3. Federal University of Maranhão, São Luis, MA, Brazil.

Submitted in November 05, 2013.

Accepted for publication in February 17, 2014.

Conflict of interests: none.

Correspondence to:

Érica Brandão de Moraes Vieira

Av. Bahia, Condomínio Gran Village Turu III, casa 28

65065-770 São Luís, MA, Brasil.

E-mail: enfermeira_erica@yahoo.com.br

(C) Sociedade Brasileira para o Estudo da Dor

\section{RESUMO}

JUSTIFICATIVA E OBJETIVOS: A dor do tipo breakthrough ocorre com frequência em pacientes oncológicos e é pouco estudada no Brasil. Este estudo teve como objetivo estudar as características da dor do tipo breakthrough e comparar a evolução durante três dias.

METODOS: Trata-se de um estudo longitudinal em que foi aplicado um questionário específico criado para a pesquisa e composto por dados sociodemográficos (idade, gênero, estado civil, profissão, renda, procedência), dados referentes ao câncer (tipos de tumor primário, existência de metástase, abordagem terapêutica como quimioterapia e/ou radioterapia, tratamento cirúrgico e fármacos) e parâmetros referentes à dor do tipo breakthrough (número de episódios por dia, duração da crise, intensidade, velocidade de inicio da dor e as variedades de dor do tipo breakthrough: espontânea, incidental e falha do fármaco no final da dose).

RESULTADOS: A maioria era do gênero feminino $(71,7 \%)$, com idade de 30 a 50 anos $(41,7 \%)$, realizava quimioterapia e radioterapia concomitante $(41,7 \%)$, e tinha câncer de colo uterino $(54,2 \%)$. A média da intensidade dolorosa foi 7 , com desvio padrão de 2,3 . Em relação à presença de dor do tipo breakthrough, não houve diferença estatisticamente significativa nos três momentos de avaliação. Durante as três avaliaçóes observou-se que houve redução no percentual de pacientes que sentiam dor com tempo acima de 15 minutos na terceira avaliação $(p=0,004)$. Náo houve diferença entre as três avaliações quanto ao perfil farmacológico $(p=0,34)$.

CONCLUSÁO: A dor do tipo breakthrough foi frequente na população estudada. O uso de opioides mostrou eficácia na diminuição do tempo de dor e dor espontânea.

Descritores: Dor incidental, Dor irruptiva, Dor neoplásica, Opioide.

\section{INTRODUCTION}

Pain may be present at any moment during disease and may be triggered by different mechanisms, such as direct tumor participation, anti-cancer therapies and other non-cancer related causes ${ }^{1}$. In addition, many cancer patients look for health professionals due to pain, which may be the first sign of malignancy ${ }^{2-4}$.

A review article has shown that the prevalence of cancer pain in patients with metastases or advanced disease is 64\%, while this prevalence is almost twice as lower in healed patients. It 
also reveals that most patients (59\%) under anti-cancer treatment refer pain. Pain was evaluated as moderate to severe by approximately one third of patients 5 .

This issue is added to the fact that the number of cancer survivors will significantly increase in the next decade and that the evaluation of the quality of life of such patients should go beyond simple evaluation of survival and should include new concerns, such as chronic and persistent pain, which may follow them for decades ${ }^{6}$. Another major concern is that, in spite of effective treatments being available in 70 to $90 \%$ of cases, there is inadequate treatment in 40 to $50 \%$ of patients, thus further increasing their pain complaints and intensity ${ }^{4}$. Pain relief may be achieved by more than $75 \%$ of patients receiving adequate analgesic treatment by pharmacological approaches, such as adjuvant opioids, as suggested by World Health Organization's (WHO) analgesic ladder ${ }^{7}$. In this context, health professionals should be attentive because there are several barriers to cancer pain treatment which generate discrepancy between improvement expectations and actual relief. Some of these barriers are lack of health professionals knowledge, attitude toward pain as a minor symptom, lack of objective methods for pain evaluation, inadequate education of patients and their relatives about the issue, and difficult access to opioids in some places, among others ${ }^{8,9}$.

Within such a broad issue, the study of breakthrough pain has gained importance in recent years, for being extremely related to poorer quality of life regardless of treatment, and for being a not well known entity, resulting in underdiagnosis, being undervalued and without necessary interventions $s^{10,11}$.

The word breakthrough appeared in the medical literature 20 years ago and defines a transient pain exacerbation in patients with moderate or mild baseline pain ${ }^{12}$. Some years after it was defined as "pain exacerbation in patients with stabilized baseline pain and receiving therapy with opioids", thus characterizing the need for previous use of potent analgesics for its control ${ }^{13}$. There are many controversies and different definitions, but it is important to consider breakthrough pain as a pain "leakage" in patients with baseline pain already being adequately treated and controlled ${ }^{10,11}$.

Since its first description ${ }^{12}$, it was recognized as important aspect of cancer treatment, fact which is proven by the increasing number of reviews and recommendations published in recent years ${ }^{11,14,15}$. For a long time, the meaning of this term has remained obscure in several languages due to lack of translation, explaining the fact that today the term breakthrough is being progressively adopted by different countries in different continents, including Brazil. Terms such as "rupture pain" and "incidental pain" have been used, but due to the difficulty of standardization or consensus, the original English term is maintained ${ }^{12,16}$.

Breakthrough pain is characterized by fast onset (less than 3 minutes), very severe intensity and short duration (approximately 30 minutes) with, in average, four episodes per day. The pathophysiology of this pain may have somatic, visceral or neuropathic etiology and characteristic, being most of the times associated to the same mechanism triggering baseline pain $^{12,13,15,17,18}$. According to the triggering event, it is classified in three types: spontaneous, incidental (related to movement) and failure at the end of therapeutic dose (which occurs in the interval between one dose and the beginning of the next dose of the analgesic used to control baseline pain $)^{12}$. A prevalence study carried out in Catalonia (Spain) with 397 patients has shown that $41 \%$ (163) of cancer patients had at least one breakthrough pain episode in a 24-hour interval, showing how significant is the problem ${ }^{19}$.

More studies are needed to estimate the actual prevalence of this pain among cancer patients, especially in Brazil where no reference was found in the specialized literature about this situation still considered unknown by physicians. So, this study aimed at studying breakthrough pain characteristics and at comparing the evolution during three days in a cancer reference hospital.

\section{METHODS}

This is a longitudinal prospective study with patients with cancer and breakthrough cancer pain.

For sample calculation, the number of adult oncology beds existing in the hospital $(n=42)$ and the prevalence of breakthrough cases found in previous studies ( 40 to $80 \%)^{13,19,20}$ were used. Sample size was defined as 24 patients with this type of pain.

Inclusion criteria were hospitalized patients above 18 years of age, under opioids for at least two months with controlled baseline cancer pain. Exclusion criteria were terminal patients, with difficulties to understand and communicate, with neurological and psychiatric problems and aged 75 years or above.

A specific questionnaire developed for the research and made up of sociodemographic data (age, gender, marital status, profession, income, origin), cancer-related data (types of primary tumor, presence of metastasis, therapeutic approach such as chemotherapy and/or radiotherapy, surgical treatment and drugs) and breakthrough pain-related parameters (number of episodes per day, duration of crisis, intensity, velocity of pain onset and types of breakthrough pain: spontaneous, incidental and failure at the end of drug dose) was applied.

Patients were included in the study after having agreed and signed the Free and Informed Consent Term, thus complying with the principles of the Declaration of Helsinki.

Data were collected during six months by the Pain Academic League, Federal University of Maranhão team.

After applying the questionnaire, patients with breakthrough pain were followed up with three evaluations with 2-day interval between them, to observe the development and characteristics of such disease. During this follow up, only parameters related to breakthrough pain were evaluated (Figure 1). Data were entered in two copies which were then compared for error correction. Statistical analysis was performed with the program Stata 10.0. Data are shown in frequency, mean and standard deviation. Friedman test was used to check whether there were statistically significant differences in the 


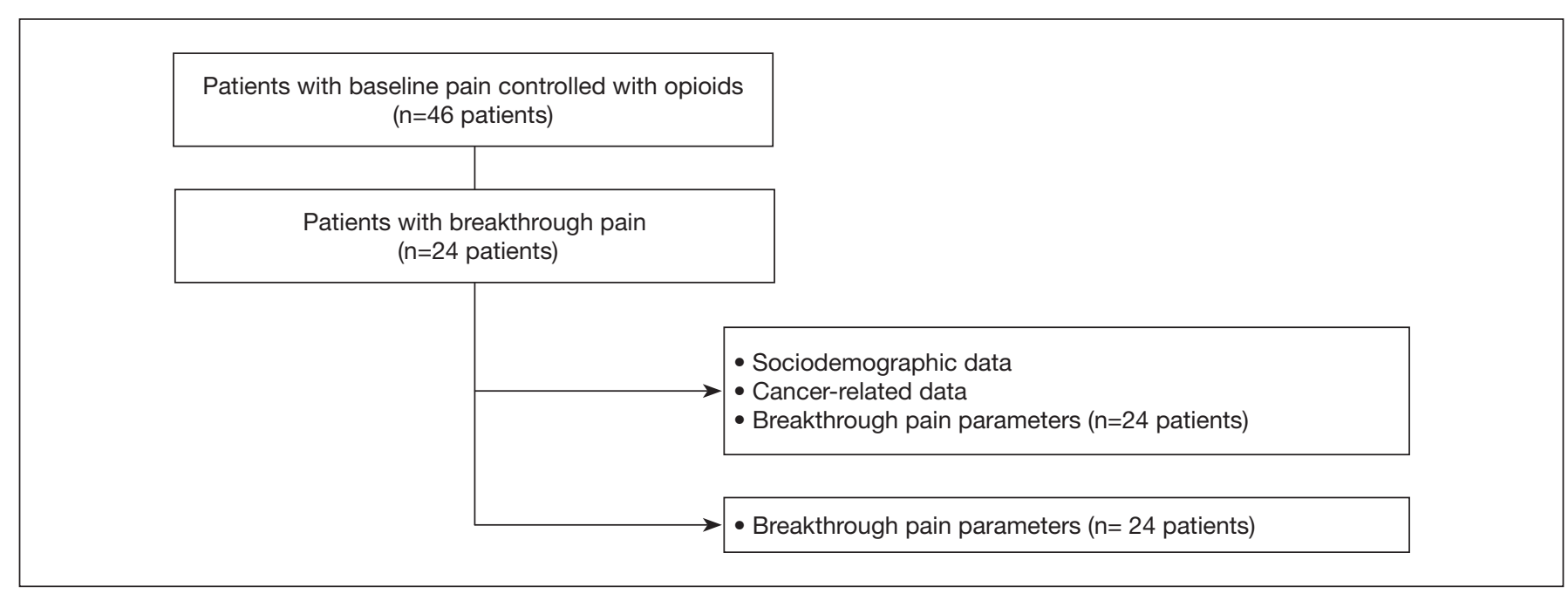

Figure 1. Flowchart of the study

three days of breakthrough pain follow up, considering statistically significant $\mathrm{p}<0.05$.

The study was approved by the Institution's Ethics Committee under n. 2954/2011.

\section{RESULTS}

Forty-six patients met the inclusion criteria, being 33 (71.7\%) females and 13 (28.2\%) males. From these, 24 (52.2\%) patients had breakthrough pain episodes.

From 24 evaluated patients, most were females (75\%), aged between 30 and 50 years (41.7\%) and self-reported skin color as black (58.3\%). Most common marital status was married or stable union $(58.3 \%)$. More than half had less than 8 years of education (54.2\%). With regard to professional activity no respondent was active and $29.2 \%$ were in medical leave due to cancer. Most patients $(75 \%)$ came from the hinterland of the state (Table 1).

According to cancer-related data, more than half had as primary site the cervix $(54.2 \%)$. Disease duration has widely varied, however most were in the first year of disease (33.4\%). Approximately $37.5 \%$ had already some type of metastasis (Table 2 ).

With regard to therapeutic approach, most were under simultaneous chemotherapy and radiotherapy (41.7\%), and 54.2\% had been already submitted to cancer surgical procedure. Approximately $65 \%$ were under strong opioids associated to analgesics (Table 2).

All patients have reported pain for more than three months and most had continuous pain (58.3\%). Mean pain intensity was 7 , with standard deviation of 2.3. Most reported pain characteristics were jumping (54.2\%) and tugging (50.0\%). Sensitivity related to pain site was preserved in $79.3 \%$. Approximately $70.8 \%$ have reported movement restriction and sleep disorders due to pain (Table 3).
Table 1. Sociodemographic data of patients with breakthrough pain

\begin{tabular}{lc}
\hline Variables & $\mathrm{n}(\%)$ \\
\hline Gender & \\
Male & $6(25.0)$ \\
Female & $18(75.0)$ \\
Age (years) & \\
$<30$ & $5(20.8)$ \\
$30-50$ & $10(41.7)$ \\
$>50$ & $9(37.5)$ \\
Color & \\
$\quad$ White & $6(25.0)$ \\
Mulato & $4(16.7)$ \\
Black & $14(58.3)$ \\
Marital status & \\
Married/stable union & $14(58.3)$ \\
Single & $9(37.5)$ \\
Widower & $1(4.2)$ \\
Education (years) & \\
$<8$ & $13(54.2)$ \\
$\geq 8$ & $11(45.8)$ \\
Professional activity & \\
Active & $18(75.0)$ \\
Medical leave & \\
Retired & \\
No remunerated activity & $7(29.2)$ \\
\hline Capin & $5(20.8))$ \\
\hline
\end{tabular}


Table 2. Cancer and treatment-related data of patients with breakthrough pain

\begin{tabular}{|c|c|}
\hline & $\mathrm{n}(\%)$ \\
\hline \multicolumn{2}{|l|}{ Primary cancer site } \\
\hline Cervix & $13(54.2)$ \\
\hline Breast & $4(16.7)$ \\
\hline Others & $7(29.1)$ \\
\hline \multicolumn{2}{|l|}{ Disease duration (years) } \\
\hline$<1$ & $8(33.4)$ \\
\hline 1 to 2 & $5(20.8)$ \\
\hline 2 to 3 & $6(25.0)$ \\
\hline$>3$ & $5(20.8)$ \\
\hline \multicolumn{2}{|l|}{ Presence of metastases } \\
\hline Yes & $9(37.5)$ \\
\hline No & $15(62.5)$ \\
\hline \multicolumn{2}{|l|}{ Therapeutic approach } \\
\hline Radiotherapy alone & $7(29.2)$ \\
\hline Chemotherapy alone & $5(20.8)$ \\
\hline Chemotherapy + radiotherapy & $10(41.7)$ \\
\hline W/o chemotherapy and w/o radiotherapy & $2(8.3)$ \\
\hline \multicolumn{2}{|l|}{ Surgical procedures } \\
\hline Yes & $13(54.2)$ \\
\hline No & $11(45.8)$ \\
\hline \multicolumn{2}{|l|}{ Analgesic treatment } \\
\hline Strong opioids + NSAIDs & $16(66.7)$ \\
\hline Weak opioids + NSAIDs & $6(25.0)$ \\
\hline Strong opioids alone & $2(8.3)$ \\
\hline
\end{tabular}

NSAIDs: non-steroid anti-inflammatory drugs.
Table 3. Pain characteristics as reported by patients

\begin{tabular}{|c|c|}
\hline Variables & $\mathrm{n}(\%)$ \\
\hline \multicolumn{2}{|l|}{ Pain onset } \\
\hline$<3$ months & $0(0.0)$ \\
\hline$\geq 3$ months & $24(100.0)$ \\
\hline \multicolumn{2}{|l|}{ Periodicity } \\
\hline Continuous & $14(58.3)$ \\
\hline Intermittent & $10(41.7)$ \\
\hline Pain intensity (NS) & $7(2,3)$ * \\
\hline \multicolumn{2}{|l|}{ Pain characteristics ** } \\
\hline Burning & $7(29.1)$ \\
\hline Flashing & $4(16.7)$ \\
\hline Jumping & $13(54.2)$ \\
\hline Tugging & $12(50.0)$ \\
\hline Pressing & $6(25.0)$ \\
\hline Heavy & $5(20.8)$ \\
\hline Throbbing & $3(12.5)$ \\
\hline Stabbing & $1(4.1)$ \\
\hline \multicolumn{2}{|l|}{ Sensitivity } \\
\hline Preserved & 19 (79.3) \\
\hline Alodynia & $1(4.1)$ \\
\hline Hypoesthesia & $2(8.3)$ \\
\hline Hyperalgesia & $2(8.3)$ \\
\hline \multicolumn{2}{|l|}{ Sleep disorders } \\
\hline Yes & $17(70.8)$ \\
\hline No & $7(29.2)$ \\
\hline \multicolumn{2}{|l|}{ Movement restriction } \\
\hline Yes & $17(70.8)$ \\
\hline No & 7 (29.2) \\
\hline
\end{tabular}

NS: numerical scale; ${ }^{*}$ Mean (standard deviation); ${ }^{*}$ Values do not add $100 \%$ because patients could give more than one characteristic to their pain.

end of opioid dose $(\mathrm{p}<0.001)$ (Table 4).

Episodes have lasted up to 15 minutes in more than half the patients during the three evaluations. However, there has been decrease in the percentage of patients with pain for more than 15 minutes in the third evaluation $(\mathrm{p}=0.004)$ (Table 4).

Six patients (25.0\%) have received no drug to control breakthrough pain and $18(75.0 \%)$ have used drugs to control pain at the first interview. Pattern was similar for second and third evaluations $(p=0.40)$. Among prescribed drugs there were subcutaneous and/or intravenous morphine, and intravenous dipirone and tramadol. There have been no differences in pharmacological profile among the three evaluations $(\mathrm{p}=0.34)$. When asked about drugs effectiveness, only five patients $(25 \%)$ have answered that they had adequate relief (Table 4). 
Table 4. Analysis of breakthrough pain episodes

\begin{tabular}{|c|c|c|c|c|}
\hline Variables & $\begin{array}{c}1^{\text {st }} \text { evaluation } \\
n(\%)\end{array}$ & $\begin{array}{c}2^{\text {nd }} \text { evaluation } \\
n(\%)\end{array}$ & $\begin{array}{c}3^{\text {rd }} \text { evaluation } \\
n(\%)\end{array}$ & $p$ value ${ }^{\star}$ \\
\hline Breakthrough pain & & & & 1.00 \\
\hline No & $0(0.0)$ & $2(8.3)$ & $1(4.2)$ & \\
\hline Number of episodes & & & & 0.93 \\
\hline Up to 5 & $19(79.0)$ & $21(95.5)$ & $22(95.7)$ & \\
\hline Numerical scale & $8.04(1.16) / 6-10^{\star *}$ & $7.85(1.15) / 5-9^{\star \star}$ & $8.00(1.09) / 5-9^{* *}$ & 0.01 \\
\hline Type of breakthrough pain & & & & $<0.001$ \\
\hline Incidental & $12(50.0)$ & $11(50.0)$ & $12(52.0)$ & \\
\hline Spontaneous & $12(50.0)$ & $8(36.0)$ & $7(30.0)$ & \\
\hline Up to 15 & $13(54.0)$ & $12(54.0)$ & $15(65.0)$ & \\
\hline$>15$ & $11(45.0)$ & $10(45.0)$ & $8(35.0)$ & \\
\hline Received drug & & & & 0.40 \\
\hline Yes & $18(75.0)$ & $17(77.3)$ & $17(73.9)$ & \\
\hline No & $6(25.0)$ & $5(22.7)$ & $6(26.1)$ & \\
\hline Drug receveid & & & & 0.34 \\
\hline Dipirone & $4(22.2)$ & $1(5.9)$ & $2(11.7)$ & \\
\hline Tramadol & $2(11.1)$ & $2(11.7)$ & $2(11.7)$ & \\
\hline Morphine & $12(66.7)$ & $13(76.5)$ & $13(76.6)$ & \\
\hline
\end{tabular}

*Friedman test; ${ }^{* \star}$ Mean (standard deviation)/min-max.

\section{DISCUSSION}

The prevalence of cancer patients with breakthrough pain episodes in our study was $52.2 \%$, lower than what has been observed in the American research $(51 \%)^{13}$ and in the British study $(72.5 \%)^{21}$, however very similar to the Spanish study by Gómez-Batiste et al. $(41 \%)^{19}$. Variation described in the literature is 40 to $80 \%$ of cases in cancer patients ${ }^{21,22}$, which shows that this is a common problem deserving being diagnosed and treated.

Most patients were young females, which was different from previous references which have not shown significant differences in gender and have recorded mean age around the sixth decade of life $\mathrm{e}^{13,19,21}$. These differences might be explained by the much higher prevalence of gynecological tumors found in the institution, which is a reference center for the state, especially cervical cancer, which is more related to younger age groups than most tumors, resulting in a large number of beds available to admit females ${ }^{23}$.

The profile of primary tumors found in this study was differ- ent from the profile found by European and North-American studies. A study in the United Kingdom ${ }^{14}$ has shown that most diagnosed primary tumors were: breast cancer $(21 \%)$, prostate cancer $(21 \%)$, colorectal cancer (10\%), myeloma $(10 \%)$, lung cancer $(7.5 \%)$ and others $(<5 \%)^{15,21}$. In this study, the number of cervical cancers is less than $5 \%$ of patients, quite different from our study where the major cause is this tumor. The reason for such difference may be the fact that the incidence of cervical cancer is twice as high in developing countries as compared to developed countries ${ }^{24,25}$. In 2010, Brazil had 18 cases per 100 thousand inhabitants, while Western Europe countries had less than 10 cases per 100 thousand inhabitants ${ }^{23}$.

The incidence of cervical cancer is even higher when the state of Maranhão is evaluated, where the incidence in 2012 was 22.49 cases per 100 thousand inhabitants; the incidence of breast cancer in this state was 11.91 cases per 100 thousand inhabitants, thus explaining the large number of cervical cancers as compared to breast cancers among participants of this study $^{23}$. Confirming this profile, there has been low educa- 
tion level and lack of remuneration in the studied sample, with most patients illiterate or just with incomplete elementary school and unemployed. Low education and poverty are closely related to high incidence of cervical cancer, because it is closely associated to sexually transmitted diseases and to the lack of prevention knowledge and information.

Cancer pain was controlled in $75 \%$ of patients with strong opioids (morphine) and in 25\% with weak opioids (tramadol) with or without adjuvants. In the study ${ }^{19}$ most have also used strong opioids, but not only morphine. Other drugs, such as methadone, fentanyl and oxycodone were also prescribed, increasing the spectrum of therapeutic options. This may reflect a broader use of morphine to treat cancer pain in our country, as well as low availability of other potent opioids for Single Health System patients.

From 20 patients reporting breakthrough pain, most (60\%) had in average two to four episodes per day during the first interview; this number was higher for subsequent interviews $(80 \%)$, similar to the average of one to four episodes per day found in other studies ${ }^{1,13,20,21}$. The increase observed during second and third interviews was expected, since characteristics of breakthrough pain were explained to patients, thus allowing for better understanding and easy identification, resulting in further requests for assistance (70\%).

With regard to the development of pain, this study was different from the study carried out in Catalonia where pain was faster in $60 \%$ of cases, versus $45 \%$ in our study ${ }^{19}$. This difference might have been caused by the high number of patients with metastases (53\%) in the Catalan study, which may accelerate pain onset. In our study, only $30 \%$ of patients had metastases. About episode duration, both studies showed similar intervals, varying from few minutes to one hour, with predominance of pain lasting 15 to 30 minutes, which was also observed by other authors ${ }^{12,13,26}$.

Pain intensity for all breakthrough cases was moderate and/ or severe. In a study by Davies et al. ${ }^{14,21}$, more than $90 \%$ of patients had moderate and/or severe pain showing a very similar situation to that of this study. Other studies have considered breakthrough pain in general severe, poorly tolerated and with major interference in the quality of life of people ${ }^{10,27,28}$.

As to classification, most breakthrough cases were incidental, having as major subtype movement; and the lowest prevalence was failure at the end of opioid dose. These results were similar to remaining studies which have also presented incidental pain and movement as major causes for breakthrough pain $^{12,13,19,21}$. These data call the attention to the limitation that this pain may bring to patients, restricting their movement in bed, preventing ambulation and even simple care such as personal hygiene.

Approximately $70 \%$ of patients used drugs to control pain, however only $25 \%$ had relief. Parenteral routes were the routes of choice for hospitalized patients, but are not the ideal alternative to treat breakthrough pain because this complaint has short duration, while drugs take longer to start acting by intravenous and subcutaneous routes. The use of transmu- cosal fentanyl (sublingual or oral) is widely discussed as an effective method to control breakthrough pain, being increasingly prescribed in Europe due to its fast onset. In Brazil, we still don't have this pharmaceutical presentation, which restricts the possibilities of treatment. Other drug mentioned is ketamine, which was effective when used by the nasal route, by spraying low doses; however this presentation is also not available in Brazil ${ }^{21,29}$.

\section{CONCLUSION}

As from this study, one may infer that the prevalence of breakthrough pain is high, was more frequent in young females with low education, with cervical and breast cancer, presenting two to four episodes per day, of short duration, severe intensity and gradual onset, and especially incidental pain. Opioids were effective to decrease pain duration and spontaneous pain.

With these data we have identified that this type of pain is a common oncologic situation, although being poorly known and highly underdiagnosed by physicians and the general population. So, it is inadequately treated leading to poorer quality of life of patients with such disease. Results of our study may help the design of other studies and the development of professional qualification programs on the treatment of this pain, allowing better assistance to patients.

\section{REFERENCES}

1. Minson F, Garcia J, Júnior J, Siqueira J, Júnior L. II Consenso Nacional de Dor On-

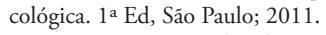

2. Vieira EB, Garcia JB, da Silva AA, Mualem Araújo RL, Jansen RC. Prevalence, characteristics, and factors associated with chronic pain with and without neuropathic characteristics in São Luís, Brazil. J Pain Symptom Manage. 2012;44(2):239-51.

3. WHO. Nacional cancer control programmes: policies and management guidelines. $2^{\mathrm{a}}$ Ed, 2002.

4. Deandrea S, Montanari M, Moja L, Apolone G. Prevalence of undertreatment in cancer pain. A review of published literature. Ann Oncol. 2008;19(12):1985-91.

5. van den Beuken-van Everdingen MH, de Rijke JM, Kessels AG, Schouten HC, van Kleef M, Patijn J. Prevalence of pain in patients with cancer: a systematic review of the past 40 years. Ann Oncol. 2007;18(9):1437-49.

6. Sun V, Borneman T, Piper B, Koczywas M, Ferrell B. Barriers to pain assessment and management in cancer survivorship. J Cancer Surviv. 2008;2(1):65-71.

7. WHO. Achieving balance in national opioids control policy: guidelines for assessment. $1^{\text {a }}$ Ed. 2000.

8. MacDonald DJ, Sarna L, van Servellen G, Bastani R, Giger JN, Weitzel JN. Selection of family members for communication of cancer risk and barriers to this communication before and after genetic cancer risk assessment. Genet Med. 2007;9(5):275-82.

9. Rhiner MI, von Gunten CF. Cancer breakthrough pain in the presence of cancerrelated chronic pain: fact versus perceptions of health-care providers and patients. J Support Oncol. 2010;8(6):232-8.

10. Zeppetella G. Breakthrough pain in cancer patients. Clin Oncol (R Coll Radiol). 2011;23(6):393-8.

11. Haugen DF, Hjermstad MJ, Hagen N, Caraceni A, Kaasa S, (EPCRC) EPCRC. Assessment and classification of cancer breakthrough pain: a systematic literature review. Pain. 2010;149(3):476-82.

12. Portenoy RK, Hagen NA. Breakthrough pain: definition, prevalence and characteristics. Pain. 1990;41(3):273-81.

13. Portenoy RK, Payne D, Jacobsen P. Breakthrough pain: characteristics and impact in patients with cancer pain. Pain. 1999;81(1-2):129-34.

14. Davies AN, Dickman A, Reid C, Stevens AM, Zeppetella G. The management of cancer-related breakthrough pain: recommendations of a task group of the Science Committee of the Association for Palliative Medicine of Great Britain and Ireland. Eur J Pain. 2009;13(4):331-8.

15. Davies AN. Cancer-related breakthrough pain. Br J Hosp Med (Lond). 2006;67(8):414-6

16. Mercadante $S$, Arcuri E. Breakthrough pain in cancer patients: pathophysiology and treatment. Cancer Treat Rev. 1998;24(6):425-32. 
17. Caraceni A, Martini C, Zecca E, Portenoy RK, Ashby MA, Hawson G, et al. Breakthrough pain characteristics and syndromes in patients with cancer pain. An international survey. Palliat Med. 2004;18(3):177-83.

18. Zeppetella G, O'Doherty CA, Collins S. Prevalence and characteristics of breakthrough pain in cancer patients admitted to a hospice. J Pain Symptom Manage. 2000;20(2):87-92.

19. Gómez-Batiste X, Madrid F, Moreno F, Gracia A, Trelis J, Nabal M, et al. Breakthrough cancer pain: prevalence and characteristics in patients in Catalonia, Spain. J Pain Symptom Manage. 2002;24(1):45-52.

20. Portenoy RK, Bruns D, Shoemaker B, Shoemaker SA. Breakthrough pain in community-dwelling patients with cancer pain and noncancer pain, part 1: prevalence and characteristics. J Opioid Manag. 2010;6(2):97-108.

21. Davies AN, Vriens J, Kennett A, McTaggart M. An observational study of oncology patients' utilization of breakthrough pain medication. J Pain Symptom Manage. 2008;35(4):406-11.

22. Mercadante S, Radbruch L, Caraceni A, Cherny N, Kaasa S, Nauck F, et al. Episodic (breakthrough) pain: consensus conference of an expert working group of the Euro- pean Association for Palliative Care. Cancer. 2002;94(3):832-9.

23. INCA. Estimativa 2012: incidência de câncer no Brasil, 2012.

24. Jemal A, Bray F, Center MM, Ferlay J, Ward E, Forman D. Global cancer statistics. CA Cancer J Clin. 2011;61(2):69-90.

25. Parkin DM, Bray F, Ferlay J, Pisani P. Global cancer statistics, 2002. CA Cancer J Clin. 2005;55(2):74-108.

26. Mercadante S, Adile C, Torta R, Varetto A, Fulfaro F, Giarratano A, et al. Meaningful cut-off pain intensity for breakthrough pain changes in advanced cancer patients. Curr Med Res Opin. 2013;29(1):93-7.

27. Zeppetella G. Evidence-based treatment of cancer-related breakthrough pain with opioids. J Natl Compr Canc Netw. 2013;11(Suppl 1):S37-43.

28. Manchikanti L, Singh V, Caraway DL, Benyamin RM. Breakthrough pain in chronic non-cancer pain: fact, fiction, or abuse. Pain Physician. 2011;14(2):E103-17.

29. Mercadante S, Costanzo BV, Fusco F, Buttà V, Vitrano V, Casuccio A. Breakthrough pain in advanced cancer patients followed at home: a longitudinal study. J Pain Symptom Manage. 2009;38(4):554-60. 